\title{
El lejano referente: ficciones de Japón en Shiki Nagaoka: una nariz de ficción ${ }^{1}$
}

THE FAR REFERENT: FICTIONS ABOUT JAPAN IN SHIKI NAGAOKA: A NOSE FOR FICTION

\section{David Issai Saldaña-Moncada*}

* Universidad Nacional Autónoma de México, México

Correo-e: david.salmon 117 (a) gmail.com

Recibido: 26 de mayo de 2020 Aprobado: 6 de abril de 2021
Resumen: La obra de Mario Bellatin ha sido objeto de múltiples estudios, entre los que destaca una visión de lo japonés cuya complejidad fomenta lecturas apegadas a la representación como realidad o 'mentira'. Sin embargo, no se ha articulado una noción de mundo ficcional consistente que explique cómo se representa la cultura japonesa. El objeto de este trabajo es desplazar el enfoque crítico realista hacia coordenadas propias de la ficción, donde lo que cobra relevancia es la forma de configurar una realidad mimética, no los hechos históricos de los que parte. El análisis detallado de los canales intertextuales presentes en Shiki Nagaoka: una nariz de ficción muestra qué tanto se representa o simboliza la cultura y la tradición literaria japonesa. Las perspectivas teóricas de la ficción y la metaficción apuntalan este enfoque, pues destacan la ficcionalidad de un mundo con anclajes discursivos y referenciales que invitan a buscar escritores japoneses desconocidos.

Palabras clave: referencialidad; ficción; metaficción; símbolo; literatura japonesa

Abstract: Mario Bellatin's oeuvre has been object of multiple studies, among which distinguishable is a vision of the Japanese, whose complexity foster readings that take representation as reality or 'a lie'. However, no consistent notion of the fictional world has been articulated to explain how Japanese culture is to be represented. The goal of this work is to move the realist critical focus to areas proper to fiction, where what becomes relevant is the form of configuring a mimetic reality, not the historic facts it is produced from. The thorough analysis of the intertextual channels presented in Shiki Nagaoka: a nose for fiction shows the extent to which literary and Japanese culture and literary tradition are represented or symbolized. The theoretical perspectives of fiction and metafiction support this approach because they underscore the fictionality of a world with discursive and referential anchors that invite to search for unknown Japanese writers.

Keywords: referenciality; fiction; metafiction; symbol; Japanese literature

1 Este artículo es resultado de una investigación desarrollada en el Programa de becas posdoctorales de la Universidad Nacional Autónoma de México (UNAM), México, en el Centro Regional de Investigaciones Multidisciplinarias, Campus Cuernavaca, Programa de estudios de lo imaginario, con la asesoría del Dr. Óscar Figueroa Castro. 


\section{LA PRODUCTIVIDAD DE FICCIÓN}

Un texto literario, sea cual sea su género, tema o estética, puede considerarse exitoso si logra generar tantos lectores e interpretaciones académicas como lo ha hecho en los últimos años Shiki Nagaoka: una nariz de ficción (2001), ${ }^{2}$ del escritor mexicano-peruano Mario Bellatin. La crítica se ha centrado en dos aspectos generales de la obra con la intención de problematizar la inclusión de referentes japoneses en el texto: por un lado, una vertiente sostiene que, en consonancia con otros textos del autor, hay una suerte de experimentación formal, en ocasiones ligada con una tendencia posmodernista en su faceta latinoamericana, para la cual Japón resulta un elemento más en una serie de concatenaciones temáticas (Schmukler, Palaverisch); la otra vertiente se enfoca directamente en las relaciones de la literatura de Bellatin con Japón, con resultados más o menos dispares, pues mientras algunos críticos deciden defender un cierto grado de representatividad en Shiki Nagaoka... (Carlsen, Riger Tsurumi), otros tratan de complejizarlo mediante diversos conceptos de la teoría literaria, desde Roland Barthes hasta una aproximación parcial con la teoría de la ficción y los mundos posibles (López-Calvo y Arrieta Domínguez, respectivamente). ${ }^{3}$

Pero ¿en qué ha triunfado el texto de Bellatin? ¿Qué es lo que arriesga en los aspectos formales y temáticos mencionados para propiciar tal cantidad de aproximaciones? En el presente artículo

2 En adelante me referiré al texto solo como Shiki Nagaoka... Las citas se tomarán de la edición de 2001, publicada por Sudamericana. Al hablar del personaje sobre el que versa el libro, lo mencionaré como Nagaoka Shiki, estilo que predomina en el interior de la obra.

3 Esta breve caracterización no pretende encasillar las aportaciones de la crítica, sino destacar la propensión a leer lo ficcional desde dos polos, concordantes con la definición común de la categoría 'ficción': unos disputan la referencialidad, apegada a la idea de representación como verdad; otros permiten una interacción más libre con el concepto, pero siempre por medio de términos como 'engaño' o 'falsedad', a veces, alentados por el propio autor. Aunque productiva, esta polaridad vicia las interpretaciones y las distrae del carácter metaficcional de la obra. busco añadir una perspectiva más a la ya nutrida discusión sobre Shiki Nagaoka... con base en dos perspectivas: la teoría de la ficción y los mundos posibles y la metaficción. Aunque parezca agotada la discusión de una obra breve (presumiblemente, 37 páginas 'del autor' de 83 que conforman el libro), me interesa puntualizar ciertos referentes literarios y las relaciones que estos entrañan, pues poseen un peso semántico específico desde el cual se problematizan elementos de la cultura japonesa. Esta voluntad de cuestionamiento trasciende a un plano de interpretación general en el que el concepto de otredad juega un papel muy importante y se relaciona estrechamente con la referencialidad, la representatividad y lo ficcional.

Poco se ha reflexionado sobre la distancia entre lo enunciado y su supuesto referente: en Shiki Nagaoka... el distanciamiento busca desaparecer al autor, cuestionar la materialidad del texto y, en última instancia, acude a mecanismos de referencialidad socavada mediante la autorreflexividad, que desdobla identidades y presiona esos límites difusos entre literatura y realidad. Lo japonés, entonces, no se limita a un referente específico o a un discurso global sobre el otro, sino que se somete a una mirada crítica enfocada en destacar rasgos equiparables entre culturas. Circular como se advierte, la intención primordial de este trabajo es abordar el intrincado juego de significados, tanto en el nivel temático como en el formal, para entender cómo Bellatin proyecta esa "búsqueda de lograr que el lector no lea lo que está leyendo" (Hind, 2004: 200).

\section{Ficción, MAS NO MENTIRA: JAPÓN COMO Un CONTEXTO FRAGMENTARIO}

Vale la pena hacer un breve resumen de Shiki Nagaoka... para especificar las partes de la obra y así analizar las relaciones entre los elementos ficcionales y los efectos metaficcionales dirigidos 
a la realidad histórica japonesa. En este texto, Bellatin funge como biógrafo, pues 'reconstruye' la historia de Nagaoka Shiki, un autor desconocido para el público latinoamericano hasta 2001, año en que se publicó el libro. Lo primero que aparece ante el lector es un índice con cinco secciones no numeradas, pero sí tituladas: "Shiki Nagaoka: una nariz de ficción", "Algunas obras del autor", "Algunas obras sobre el autor", "Documentos fotográficos sobre Shiki Nagaoka", y "Dos narraciones clásicas sobre el tema de la nariz". A continuación, encontramos dos epígrafes: el primero es una frase sobre una nariz, atribuida a un "anónimo del siglo XIII"; sin otras coordenadas, lo único que se intenta transmitir es, en todo caso, su pertenencia a alguna tradición literaria; el segundo epígrafe es tomado del cuento "La nariz", de Akutagawa Ryūnosuke (Tōkyō, Japón, 1892-1927), célebre escritor japonés conocido por cuentos como "Rashōmon" o "El biombo del diablo".

En la primera sección, que comparte título con el libro y consta de 35 fragmentos no numerados, Bellatin recopila y ordena anécdotas biográficas. Se narran episodios de la vida de Nagaoka Shiki - cuyo único rasgo físico descrito es el excesivo tamaño de su nariz-, entre los que destacan sus primeros acercamientos con la literatura, siendo muy joven; después sabemos de su entrada a la vida monástica, que va acompañada de un escándalo con dos posibles causas: la primera es un desencuentro con su familia debido a su decisión de volverse monje o por escribir monogatarutsis (cuentos); la segunda plantea que esta es una forma de ocultar la relación con un sirviente, lo cual genera una fuerte disputa con sus padres y, por ello, nunca vuelve a verlos. Enseguida se narra su estancia en el monasterio Ikeno-wo, donde se recluye y es sujeto de burlas por su gran nariz y, a pesar de ellas, se dedica a escribir; por último, se cuenta su salida del monasterio para dedicarse a revelar fotografías, actividad que combina con la escritura, que evoluciona al buscar ir más allá de lo escrito.
A la par de estas anécdotas se describen brevemente los textos que conforman su obra, así como la nula relación que tuvo con el mundo literario de su país, el cual se debate entre dos posiciones: una receptiva de las ideas extranjeras y otra que rechaza su inclusión; se narra también su encuentro con un escritor japonés de renombre, Jun'ichirō Tanizaki, así como la presunta influencia que el propio Shiki ejerció en dos autores latinoamericanos: Juan Rulfo y José María Arguedas. Al final se narra su muerte, el esfuerzo de recuperación de su obra y los estudios de los que ha sido objeto en años recientes.

Las siguientes secciones son distintas, tanto en extensión como en carácter: "Algunas obras del autor" y "Algunas obras sobre el autor" abarcan dos hojas, una cuartilla por cada apartado, con sus respectivas blancas para separarlos, Estas páginas bien pueden considerarse parte de la primera sección en tanto solo compilan los textos ya mencionados y atribuidos a Nagaoka Shiki, y se añaden un par de libros que supuestamente han abordado al escritor de forma tangencial o primordial.

La cuarta sección, "Documentos fotográficos sobre Shiki Nagaoka", consta de 32 cuartillas en las cuales se presentan fotografías - una labor atribuida a Ximena Berecochea, actualmente investigadora de la University of Toronto- que pretenden ilustrar los sucesos narrados en la primera sección. Las fotos presentan imágenes con un aire oriental en lo general y, en lo particular, es fácil asociarlas a la cultura japonesa; de momento, basta decir que son fotos reales recontextualizadas. ${ }^{4}$ El libro cierra con "Dos narraciones clásicas sobre el tema de la nariz",

4 No me extenderé en el análisis de las relaciones entre fotografía y palabra, basta señalar su efecto: lo que supuestamente escribió el personaje es llevado a cabo en la obra (interacción entre secciones escritas y fotografías), con lo cual se genera un mise en abyme o ruptura del marco, que será constante en muchos niveles del texto. Como menciona Leonel Cherri (2019: 3), las imágenes no son artísticas: constituyen un archivo real llevado al plano ficcional, su efecto artístico consiste en generar una sensación de realismo y verificabilidad, cuyo límite se concreta en una verosimilitud frágil que se ha tejido mediante lo escrito. 
donde se encuentran dos textos homónimos, en concordancia con los epígrafes del inicio: el primero corresponde al anónimo del siglo XIII, sin especificar su procedencia; el segundo es el de Akutagawa Ryūnosuke y está tomado integralmente de la traducción de Kazuya Sakai, escritor y pintor nikkei que vivió varios años en México (Akutagawa, 1980: 17-25). ${ }^{5}$

Es posible notar de inmediato los ejes de la obra: en primer lugar, una disposición estructural que parece simple pero que se revela circular, lo cual es por lo menos extraño para un texto que se presenta, en lo inmediato, como una biografía. Así mismo, el nombre del autor recuperado y la aparición de Akutagawa en las primeras páginas del libro hablan ya de un vínculo con la cultura japonesa, pero icómo es este?, ¿se somete a las caracterizaciones clásicas de la intertextualidad?, iintenta dar una imagen de esta cultura a partir de un escritor (ficcional)?

Durante años, los estudiosos de Shiki Nagaoka... han avanzado paulatinamente en la interpretación del texto, deslindando, en primer lugar, a Nagaoka Shiki de la realidad factual, es decir, reconociendo que es un personaje de ficción. Sin embargo, recién publicada la obra, el personaje no se tomó como lo que fue en un principio: un invento improvisado por el 'biógrafo'.

En una nota a pie de su tesis doctoral, Ximena Berecochea reproduce una nota periodística que anunciaba una conferencia de Bellatin (2014: 91). El evento se llevaría a cabo en agosto de 2001 en el marco de una serie de conferencias tituladas "Mi escritor favorito", donde Bellatin presentó por primera vez a Nagaoka Shiki.

5 La elección de retomar la edición de Sudamericana responde a que la publicada en Obras completas presenta dos cambios significativos: en primer lugar, recorta la última sección, "Dos narraciones clásicas sobre el tema del autor", que es uno de los indicios metaficcionales más descarados a disposición del lector para comprender el carácter de las relaciones entre realidad y ficción. En segundo lugar, reordena el nombre del personaje en el título de la obra: Nagaoka Shiki: una nariz de ficción, es decir, reacomoda el nombre al estilo japonés, primero el apellido, luego el nombre de pila. Estos cambios denotan un esfuerzo reescritural que apunta a profundizar la ambigüedad de lo escrito.
Lo anterior resulta una clara muestra de cómo, según el género con el que se presenta un libro, en conjunción con el medio en el que comienza a circular, permite asumir un personaje ficcional como real, pero iesa lectura es solo la consecuencia de un engaño, de un juego? En el plano del mundo referencial, Nagaoka Shiki no solo resultaba un personaje atractivo por ser 'novedoso' (aunque 'falleció' en 1970), sino porque es avalado por Bellatin como su "escritor favorito"; además, como se lee en Shiki Nagaoka..., en la época final de su literatura fusiona activamente fotografía y escritura, es decir que sería un autor interesante por trabajar con dos formas artísticas. Un escritor tan cercano a lo que actualmente definimos como intermedialidad no podría sino llamar la atención. Estos elementos, aunados a la presentación en un ambiente 'serio', permiten una primera lectura biográfica.No obstante, esta se modificó pronto: múltiples estudios se enfocaron en el texto y Bellatin admitió la ficcionalidad del autor. A partir de 2004, con la entrevista realizada por Emily Hind, y con la de Fermín Rodríguez en 2006, Bellatin desarrolló sus líneas estéticas y deslindó a Nagaoka Shiki de la realidad histórica japonesa:

Esta biografía de Shiki Nagaoka, a mí no me interesa hablar de un autor. No me interesa que se cree una relación con el lector que transcurra por estas páginas. Yo no pretendo que la gente crea que sí es verdad o sí es mentira. Ni tampoco en el otro libro, El jardín de la señora Murakami, me interesa que crean que es Japón. Sí, que crean y después se den cuenta que no es porque el mismo texto tiene los elementos que decodifican esto y te dicen, "Oye, no seas tonto. No es Japón. Estos pies de página son inventados" (Hind, 2004: 198).

Sin embargo, esta declaración contiene una carga negativa respecto al uso del término 'ficción' fomentada por el propio Bellatin —desde mi punto de vista- como un ardid para generar un 
debate intenso entre dos términos polarizados: 'verdad' y 'mentira'. ${ }^{6}$ Estos han rondado constantemente la noción de ficción, al grado de que es común su uso negativo equiparado con 'mentira' o 'engaño', contrapuesto al valor de lo verdadero. De ahí que resulte útil hablar del término según lo expuesto por Thomas Pavel en Mundos de ficción, donde aborda el problema desde múltiples puntos de vista. Al referirse en particular a las estructuras duales, formas poco elaboradas de ficción, expone:

Sin embargo, se quiere no tanto explicar la ilusión generada por el juego de mentirillas para disiparlas y expresar lo que sucede en términos del mundo realmente real, sino más bien dar cuenta de nuestra participación durante estos juegos. Tanto en el mundo realmente real como en los mundos reales de ficción, hay que distinguir los dos niveles distintos en los cuales se despliega el juego y mostrar los vínculos que los unen (Pavel, 71-72). ${ }^{7}$

6 Bellatin tiene una opinión firme de la interpretación académica o literaria que busca el referente sin cesar, como una verdad que puede ser social o histórica: "También está esa lectura sociológica que tanto ha jodido cuando uno es joven y empieza a escribir con el peso de ese deber ser encima [...] No entiendo qué cosa es lo literario. Yo no parto de la literatura en el sentido de que quiero hacer una literatura. Parto de la palabra, y que esa palabra construya algo [...] Yo no salgo del espacio escritural" (Rodríguez y Bellatin, 2006: 64). El carácter de su literatura no puede evitar la autorreflexividad, por lo tanto, es consciente de la polémica en la formulación verdad/mentira y opta por explotarla.

7 Thomas Pavel parte de un capítulo dedicado a los mundos posibles como noción derivada de la lógica modal, con base en el trabajo de Saúl Kripke y el antecedente de Lubomír Doležel, para llegar a un ejemplo muy sencillo: la lógica de constitución de objetos ficcionales en un juego infantil, en el que se da por hecho que figuras de barro representan pastelillos. La idea de las mentirillas que juegan mediante representaciones de objetos reales viene de Kendall Walton, quien liga el problema metafísico de los entes de ficción y su estatuto ontológico con la inercia de una narrativa que 'atrapa' al espectador o lector. La relación que une el mundo real y el ficcional se formula como 'se tomará por', en el que lo ficcional es real de forma contingente y se apoya en una narrativa con una lógica básica. En el caso de Shiki Nagaoka..., sin embargo, esa lógica no pretende ser respetada en todos sus aspectos, sobre todo en lo que se refiere a lo temporal, como veremos con motivo de la época que supuestamente acoge al autor ficcional 'japonés'.
La discusión sobre lo real y lo ficcional es pertinente en tanto Nagaoka Shiki parece pertenecer a un contexto japonés, pero, en su realidad, está ligado a figuras y sucesos históricos nipones incompletos. Bellatin insiste en interpretar los referentes japoneses como un juego de mentiras para obviar que el carácter parcial es justamente lo que identifica a un personaje de ficción y esto aleja la representación del referente, pues no se busca una identificación directa. Como menciona Patricia Waugh al abordar la cuestión de la mentira en la ficción:

Our statements about literary-fictional
characters can be verified only by consulting
the statements which are those characters,
which have brought them into existence.
Metafictional novels continually alert the
reader to this consequence of the creation/
description paradox. To make a statement in
fiction is to make a character. All statements
have 'meaning' in relation to the context
in which they are uttered, but in fiction the
statement is the character is the context.
Thus characters in metafiction may explicitly
dissolve into statements. They may act in ways
totally deviant in terms of the logic of the
everyday 'commonsense' world, but perfectly
normal within the logic of the fictional world
of which they are a part (1984: 92-93) [El
subrayado es mío].

Al preguntar cuáles son los canales intertextuales y qué tanto se busca representar la cultura japonesa en el libro de Bellatin, mi intención es desplazar los discursos críticos realistas de Shiki Nagaoka... hacia coordenadas propias de la ficción, donde lo único que cobra relevancia es la forma de configurar una realidad mimética, no tanto los hechos de los que parte. ${ }^{8}$ La premisa es

8 Esto es lo que se le reclama constantemente al carácter posmoderno de la literatura de Bellatin: una supuesta voluntad de no-representación (Carlsen, 2015: 74). En conjunción con el tema del orientalismo, el reclamo acerca la interpreta- 
clara: la descripción/construcción de un personaje ficcional es equivalente a la de su contexto y este no ostenta el mismo estatuto que el discurso histórico.

El escritor parece contradecirse en cuanto a la ficción, pues la visión teórica tanto de esta como de la metaficción es acorde con la intención declarada de Bellatin de crear 'mundos autónomos': así, por un lado, habla de 'engaño' y 'mentira' $y$, por otro, busca consolidar ficciones capaces de sostenerse por sí mismas. Incluso ya se han realizado estudios con perspectivas enfocadas en explotar esa discursividad, que se concibe independiente de la realidad, pero con ciertas limitaciones. ${ }^{9}$ Basta una mirada más incisiva para caer en la cuenta de que el texto, desde su estructura, permite desechar toda cercanía con una noción de verdad y que, en lugar de buscar una representación referencial directa y simple, que permitiría el exotismo, el autor privilegia una imagen fragmentaria de Japón dirigida a lo simbólico basada en aspectos culturales:

Sería mejor decir que la conciencia dispone de distintas gradaciones de la imagen — según que esta última sea una copia fiel de la sensación o simplemente indique la cosa-, cuyos extremos opuestos estarían constituidos por la adecuación total, la presencia perceptiva, o bien por la inadecuación más extrema, es decir, un signo eternamente separado del significado. Veremos que este signo lejano no es otra cosa que el símbolo (Durand, 2007: 10).

Según Gilbert Durand, una imagen alejada del referente, entendido este como sentido exclusivo,

ción a una postura más bien peligrosa, en tanto se le adjudica al texto la intención de fragmentar todo lo proveniente de la cultura japonesa para ser tomado de manera superficial, exotista (López-Calvo, 2013: 343). Esto, sin embargo, se revela a su vez como una lectura superficial, pues la interacción con el referente es sumamente compleja.

9 López-Calvo fue uno de los primeros críticos que abordó con más detenimiento el texto de Bellatin, con una hipótesis acerca de las invenciones en torno a los referentes japoneses como elementos 'orientalizantes' (López-Calvo, 2013: 351). tiende a simbolizarse. Por lo tanto, esa autonomía de lo ficcional solo puede simbolizar los elementos tomados de la realidad factual: se constituye en una imagen particular de la cultura japonesa, la cual adquiere una serie de sentidos que desbordan lo histórico concreto. La primera llamada de atención al lector de este proceso autorreflexivo es descarada, pues se encuentra desde el inicio del texto, donde se menciona el carácter inverosímil de la nariz de Shiki Nagaoka, que llevó a considerarlo un personaje ficcional en su propio mundo. ${ }^{10}$

Esta primera descripción se desplaza de inmediato hacia la interpretación de la nariz desde un punto de vista cultural, ligada al Japón histórico únicamente mediante uno de los elementos más caros a su cultura: la polémica entre la tradición vernácula y la inclusión de ideas y productos europeos a principios del siglo XX:

Cuando vieron al niño, las mujeres discutieron sobre si aquella nariz no sería un castigo. Tanto ellas como buena parte de la sociedad habían participado del entusiasmo desmedido que motivó la invasión de ideas extranjeras. Para muchos esa alteración de los hábitos fue una verdadera bendición, y para otros un rotundo desprecio a la dignidad de la patria (11) [El subrayado es mío].

Uno de los argumentos más sólidos expuestos por la crítica consiste en equiparar las referencias al Japón histórico con la cultura de tintes nipones a la que parece pertenecer Nagaoka Shi$\mathrm{ki}$, precisamente con base en el desarrollo de un

10 Hay dos análisis interesantes del inicio de Shiki Nagaoka...; el primero corresponde al trabajo de López-Calvo, quien propone un par de interpretaciones cercanas a la ficción: una nariz imposible que inspira ficciones (2013: 342); el segundo corresponde a la tesis doctoral de Daniel Arrieta Domínguez, que analiza las afirmaciones ficcionales como recursos retóricos: la nariz como metonimia del personaje, como metáfora de un conflicto cultural, etc. (2015: 232-234). A pesar de que este último recurre a la teoría de la ficción, no se enfoca en sus implicaciones y los subsecuentes cuestionamientos que plantea en torno a la referencialidad, para continuar con la polarización verdad/mentira. 
momento sociohistórico que sustenta el mundo ficcional del personaje. ${ }^{11}$ En Japón: hacia una nueva literatura, Kazuya Sakai explora momentos fundamentales de esta historia literaria y dedica la mayor parte del volumen a los textos producidos a partir del periodo Meiji (18681912), donde surge el bundan o mundo literario, coto artístico marcado por el aislamiento social debido a la estructura confuciana heredada del periodo Tokugawa (1603-1868):

\begin{abstract}
El hecho de que la sociedad considerara inútiles tanto a la novela como a los novelistas, significaba que para esa sociedad 'sana', 'progresista' y 'mercantil' los escritores no eran otra cosa que 'seres fracasados', 'sin aspiración social', en una palabra, 'seres inmorales'. Como reacción y como defensa, los escritores levantaron una sociedad ficticia en la cual, rompiendo una tradición feudal plagada de prejuicios, pudieran vivir libremente como artistas. Desde luego no fue empresa fácil, y muy elevado en cambio el precio que pagaron. Soportaron el desprecio y la ignorancia de la gente, la pobreza, la soledad del aislamiento; pero al mismo tiempo pudieron crear una literatura y una novelística de carácter purista y de rasgos intensos y pasionales que raramente encontrará paralelo en otras épocas o países (Sakai, 1968: 44).
\end{abstract}

Este periodo histórico siempre ha sido identificado por antonomasia como el de la occidentalización de Japón. La obra de Nagaoka Shiki, si es que admite filiación temporal alguna, se ubicaría presuntamente aquí, pero Bellatin introduce un cambio importante: el nombre del periodo

11 Como ejemplo de la lectura referencial-realista destaca el trabajo de George A. Carlsen, quien constantemente rechaza los efectos metaficcionales y la primacía del ámbito ficcional sobre la referencialidad: lo fragmentario se tilda de posmoderno y la representatividad se salva de lo inventado al indicarlo como mentira o falsedad (Carlsen, 2015: 70). Esta insistencia llevará al crítico a una confusión sobre la temporalidad: insiste en situar a Shiki como autor de posguerra, cuando su obra, según lo narrado, se escribe años antes de una guerra, aunque se publique siempre a destiempo. cambia a 'Meiní' y se da a entender que fue una época antigua (14); conserva la caracterización expuesta por Sakai y lo reubica en el pasado del mundo ficcional, evitando nombrar el momento histórico que alberga la etapa más productiva de Shiki. Lo más relevante también se encuentra alterado: en lugar del bundan, el lector recibe información de un "Mundo flotante", nombre que designa un estrato sociocultural propio del periodo Tokugawa histórico. Estas alternancias entre rasgos y nombres también se observan en los dos grupos antagónicos que se disputan el alma del país de Nagaoka Shiki:

Nada le hubiera costado viajar a la gran ciudad, de la que apenas lo separaban unos kilómetros, y buscar formar parte de los creadores del Mundo Flotante, que era como se les llamaba a los artistas que solían reunirse en los establecimientos del centro de la ciudad. Gracias a su excepcional nariz no hubiera tenido problemas para unirse a ellos, ya que estos artistas rendían culto a todo lo extranjero. Por el contrario, hubiera podido afirmar que se avergonzaba del tamaño de su nariz y acercarse al grupo de los Tradicionalistas Radicales que presidía la diminuta maestra Takagashi, los que acusaban a los artistas del Mundo Flotante de traición a la patria (25-26). ${ }^{12}$

La realidad histórica resulta mucho más compleja que la postura maniquea de estos grupos, pues tanto los escritores del bundan como la sociedad en su conjunto estaban en contacto con lo occidental y cada uno lidiaba con ello

12 Es necesario reconocer el rol que ha jugado El jardín de la señora Murakami (2000) como intertexto dentro del marco macrotextual de la obra de Bellatin, cuando se ha estudiado Shiki Nagaoka. Las dos comparten mecanismos, una forma narrativa similar y personajes como la maestra Takagashi, y se les ha abordado simultáneamente para conformar una visión del 'Japón de Bellatin' como una amalgama entre las referencias de ambas obras. Si bien es posible dicha interpretación, puesto que los procedimientos referenciales de Shiki Nagaoka... se refinaron con base en la experiencia de El jardín..., la ficción sobre Japón varía estructuralmente entre una y otra. 
a su manera. Aun con todo el peso que tiene la disyuntiva modernidad/tradición en el desarrollo de la cultura japonesa, no es suficiente para afirmar que en Shiki Nagaoka... se representa el contexto de las primeras décadas del siglo XX de esta nación. Se alude a una realidad histórica, pero destaca la elisión o borradura de otras particularidades sociales vinculadas al periodo Meiji, como las bases del colonialismo de la nación oriental. En otras palabras, si la intención era hablar de Japón de manera directa, debería haber referencias a su rol imperialista durante la primera mitad del siglo XX, sin embargo, este fuerte componente se reduce a la alusión de un silencio después del desastre de la guerra, consecuencia palpable de la lucha ideológica entre los grupos arriba mencionados:

Solo cuando llegaron los años de la guerra se hizo evidente lo perjudicial que había sido la aceptación incontrolada de ideas extranjeras. La clase aristócrata se arrepintió de haber estado de acuerdo con esa política, y pidió disculpas públicas antes de que el país quedara destruido física y moralmente. Los artistas del Mundo Flotante renegaron asimismo de muchas de sus obras. Tras aquellos años, todo fue silencio (28).

El referente es parcial una vez más, pues no se habla de bombas nucleares ni de un emperador con su discurso de rendición, y es una clase la que admite su error y pide disculpas a la sociedad. La ficción reorganiza los eventos, pero mantiene la sensación de fracaso, de haber cometido errores terribles. Se mantiene la destrucción y se alude a cambios estéticos. El Mundo Flotante no es el histórico, sino una combinación entre su relación con lo urbano y el aislamiento del bundan. Entonces, se hace evidente que el modo elegido para presentar la realidad de la ficción radica en plantear temas generales y su proceso de conformación con base en fragmentos de la historia japonesa.
De manera análoga a lo que sucede en el nivel social del mundo ficcional, los elementos foráneos no son los occidentales, sino lo japonés, considerarse como externo a la obra en sí, es decir, todo aquello que viene de fuera, de la realidad, ha sido recibido de igual forma: con un entusiasmo desmedido que lleva a un lectura realista - en el mejor de los casos, a una visión mimética de la ficción creada por Bellatin-o, al contrario: se rechaza lo externo y se da por sentado que este es un universo aparte en el que existe un escritor llamado Tanizaki, y otro, Akutagawa, y estos conviven con Nagaoka Shiki y su nariz, metáfora del complejo proceso de adaptación de su nación a la influencia exterior (Schmukler, 2013: 5). Así, la ambigüedad del vínculo con el referente juega un papel central respecto de la verosimilitud de la ficción: solo resta darle el mismo crédito a ambas lecturas, pues no es posible conciliarlas sin escudriñar y desmontar sus procedimientos.

La distancia establecida entre el referente histórico y las variaciones del mundo ficcional permiten al lector partir de una base que no es un mero escenario, sino que cada situación revela una elección con un peso semántico específico, el cual gira en torno al personaje - particularmente, en torno a su nariz, que ha sido erigida como símbolo de los grandes retos a los que se enfrenta su cultura- ${ }^{13}$ Ahora bien, es necesario explorar la incorporación de nombres y textos reales al mundo de Shiki Nagaoka, pues el tratamiento que se le da a los autores y a su literatura es mucho más incisivo: se enfoca en reforzar los vínculos establecidos a nivel contextual y detona una serie de efectos metaficcionales que el propio texto representa. Esto se constata al hallar correspondencias que exceden el 'ambiente artístico' propio de la época Meiji: existe una relación mimética entre la vida de Nagaoka Shiki, la

13 Daniel Arrieta Domínguez lo apunta, pero no explora esta vía, pues el término parece ser intercambiable por representación: "Y Shiki se convierte en un símbolo de la introducción de ideas occidentales en Japón, para unos una invasión y el final de la cultura japonesa; para otros, el comienzo de su modernización y el desarrollo del país" (2015: 234). 
estética desarrollada globalmente en la obra que lo acoge y la vida de un autor japonés de inicios del siglo XX: Naoya Shiga (1883-1971).

La ambivalencia del Referente: De Naoya Shiga A NAGAOKA SHIKI

Es notable que, a pesar de la búsqueda de referentes por parte de la crítica, no se ubicara el modelo japonés del autor ficcional, aquel capaz de articular el contexto y lo anecdótico: Naoya Shiga, novelista, escritor de cuentos y uno de los máximos representantes de la shishōsetsu o 'novela del Yo' japonesa. Esta fue una tendencia narrativa de principios del siglo XX, cuya estética giraba en torno a la narración de la experiencia cotidiana con un tono íntimo. En The Rhetoric of Confession: Shishosetsu in Early Twentieth-Century Japanese Fiction, Edward Fowler dedica un capítulo a Shiga Naoya, cuya influencia se comprueba desde el epígrafe que inaugura el estudio, tomado de "Haguruma" — texto que se encuentra en un libro de ensayos de Akutagawa titulado Bungeiteki na, amari ni bungeiteki na-. La frase en cuestión se dedica a ensalzar la literatura de este autor poco conocido. ${ }^{14}$ Esta alabanza de Akutagawa es cardinal, pues refiere cómo lo real se incorpora en los niveles que son hegemónicos en lo que respecta a la ficción desplegada en el texto: el discursivo y el simbólico.

Una vez aclarada la relevancia de Shiga Naoya podemos inquirir qué es lo que lo enlaza con Shiki. En primer lugar, comparten el hecho de ser desconocidos en América Latina, aunque esto también ocurre con buena parte de los escritores japoneses de inicios del siglo XX; sus nombres son fonéticamente similares, ${ }^{15}$ pero más allá de

14 Fowler considera que la figura de Shiga Naoya es de tal relevancia que fue factor para el suicidio de Akutagawa y de otro afamado escritor: Osamu Dazai (Fowler, 1988: 188-189). A expensas de esta afirmación, lo que destaca es el rol de este escritor en el campo literario de la época, así como su centralidad en lo que respecta a la shishōsetsu. la mera coincidencia de iniciales, es posible rastrear las fuentes de las que abrevó Bellatin para retomar el contexto de esta cultura oriental y la imagen de uno de sus escritores. En ese sentido, es fundamental la presencia del mencionado Kazuya Sakai y de Javier Sologuren (1921-2004), escritor peruano, profesor universitario y uno de los más entusiastas difusores de la cultura nipona en América Latina.

Como se expuso antes, tanto la traducción del cuento de Akutagawa como la información extraída del libro de Kazuya Sakai sobre literatura japonesa son muestras inequívocas de las lecturas realizadas por Bellatin, pero no solo eso: el propio Naoya Shiga aparece referido en el capítulo siguiente a la explicación sobre el bundan:

Los escritores del grupo Shirakaba, por ejemplo, como Shiga Naoya, tenían claramente definido un ideal artístico y humano, creían firmemente en la existencia de una voluntad de la humanidad universal que los llevaba también a creer que la expansión de la personalidad era al mismo tiempo la expresión de la naturaleza humana. En otro orden, Akutagawa, en definitiva, era un convencido del personalismo. Este personalismo tendió a un liberalismo de amplios matices que no es posible encontrar en años posteriores, en los cuales la convicción en un ideal exigía automáticamente la exclusión de los otros (Sakai, 1968: 77).

Si bien es posible deducir que Bellatin se basó en la exposición de Sakai para retomar la idea del bundan, faltan datos que liguen al escritor

15 Arrieta Domínguez menciona una declaración de Bellatin en la que revela que el apellido Nagaoka fue tomado de un famoso restaurante japonés al sur de la Ciudad de México (2015: 248). También sugiere que el nombre de pila se parece al de un autor de haikú moderno que fue objeto de estudio en el último libro de Donald Keene, The Winter Sun Shines In: A Life of Masaoka Shiki, de 2013. Por el año de publicación, esta relación no es posible, en cambio, Masaoka Shiki aparece en El rumor del origen. Antología general de la literatura japonesa (1993), de Javier Sologuren, texto que Bellatin leyó y que será importante para investigar los epígrafes como muestra de los vínculos literarios con el país oriental. 
ficcional con Naoya Shiga más allá de su mera evocación como autor comprometido con un 'ideal' (vale recordar que Nagaoka Shiki siempre se apegó a su tradición). Para ahondar en lo anterior, resulta necesario recapitular el episodio que determinó la vida de Shiki: tras una breve referencia a su formación en un colegio de lenguas extranjeras - que afianza esa relación con lo otro encarnada por su nariz- decide ingresar al monasterio Ike-no-wo. Al principio, se ensaya la nariz y lo que simboliza como causa de la decisión y, de inmediato, se añade un problema amoroso como alternativa:

Se puede pensar que esos dos elementos, mezclados con la discusión aún no acallada sobre la conveniencia o no de abrirse a Occidente, lo llevaron a un callejón sin salida. Tal vez en aquellas circunstancias la reclusión religiosa fuese la única escapatoria [...] Se sabe además, aunque la hermana hiciera todo lo posible por ocultarlo, que Nagaoka Shiki en ese tiempo vivió una decepción amorosa cuando el objeto amado, un joven sirviente gordo y deforme, lo humilló haciendo públicas sus proposiciones ante las autoridades de la comunidad. Se cree que la familia trató de borrar aquel pasaje de la vida del escritor [...]. Se dice también que el verdadero repudio familiar fue originado por la denuncia del sirviente y no, como la familia sostuvo en público, por rechazar el ingreso de cualquiera de sus miembros a la vida eclesiástica (2001: 14-15).

El autor equipara la decisión de Nagaoka Shiki con un episodio biográfico de Naoya Shiga como un modelo situacional a partir de una inflexión en la vida de ambos: la disputa con la familia.

One of the reasons for Shiga's celebrated breach with his father was his decision to pursue a writing career. Shiga's father voiced a quite common sentiment: outrage that any son (but particularly the eldest, as Shiga was) born to a socially distinguished family would degrade himself by indulging in such a frivolous occupation. There is a memorable scene in Aru otoko, sono ane no shi (A certain man and the death of his sister, 1920) in which the father interrogates his son, the hero, about his plan to become a fiction writer (shōsetsuka) (Fowler, 1988: 190-191).

El paralelismo no es una coincidencia: se trata de una decisión de vida que lo aleja de la familia. Este momento también marcó de forma determinante a Naoya Shiga, aunque él sí pudo reconciliarse con su padre, cuestión retratada en una novela que lleva por título Wakai (1917), precisamente, 'reconciliación'. La pelea entre Shiga Naoya y su familia proviene de la fuerte jerarquización social de la época antes señalada. Lo más curioso de esta situación es que, de acuerdo con Fowler, Naoya Shiga no fue el único escritor japonés de Meiji que tuvo problemas con sus padres, con lo cual se confirma la tendencia social de relegar a los escritores y, con ello, se daba forma al bundan como una institución periférica en relación con el buen funcionamiento de la sociedad. Esto resuena en la premura de la familia por deslindarse públicamente de Shiki, dada su pertenencia a la clase aristocrática:

La nota señalaba también que la familia hubiera querido que Naigu Zenchi, una vez cumplida la mayoría de edad, dejara de escribir monogatarutsis para que se dedicara a administrar los negocios de la familia. Nagaoka Shiki sería desheredado en cuanto cruzara las puertas del pabellón principal del monasterio de Ike-no-wo, concluía la noticia. Nuestro autor fue efectivamente repudiado y desde entonces vivió en la pobreza (16).

Así se incluye, veladamente, el rol inconveniente o improductivo de los escritores a nivel social. Mario Bellatin apenas menciona la escritura 
como un problema para la familia y parece ficcionalizar un drama amoroso como explicación alternativa al conflicto. Sin embargo, es esta la coincidencia que causa más sorpresa: la relación de Shiki con una persona a su servicio. Naoya Shiga retrata un episodio similar en la primera novela del llamado Ciclo wakai, el cual:

It is united loosely by the theme of the hero's troubled relationship with his father. In Otsu Junkichi, the first-person narrator (a wouldbe writer) chronicles his ambivalent feelings toward his friend's sister, his special relationship with his grandmother, who raised him since he was an infant, and finally his unsuccessful attempt to marry a housemaid in the face of family opposition. The father remains in the background, although his presence is continually felt - most keenly when the narrator discovers that he was behind the maid's removal from the house. In Wakai the father again is very much in the background until the end (Fowler, 1988: 204-205) [El subrayado es mío].

Las anécdotas coinciden en estas situaciones particulares, aunque Bellatin opta por radicalizar el amorío hasta el grado de plantear que el sirviente fue asesinado por la familia en aras de limpiar su reputación, o por el propio Shiki en contubernio con su hermana por despecho; es así como el autor recurre a la ficción para crear un mundo de referencias particulares turbias, mezcladas con circunstancias sociales.

Como puede apreciarse, Nagaoka Shiki no es un personaje ligado a Naoya Shiga solo por el nombre. Las tres posibilidades para interpretar la decisión de ingresar al monasterio: un amorío prohibido y forzado, la voluntad de volverse escritor que emula un problema social del Japón histórico, o la interpretación del narrador, que incluso ve en el gesto una necesidad espiritual, empatan con niveles de representación. El primero es el del personaje, ligado con la biografía de Naoya Shiga; el segundo nivel es social y artístico, pues alude al bundan-Mundo Flotante; $y$ el tercero es un atisbo místico, el cual parte de la tendencia discursiva acerca de las filosofías orientales, elemento casi ineludible en el horizonte de los lectores. ${ }^{16}$ Por otro lado, Bellatin no deja de recurrir al vaivén entre las afirmaciones que competen a una trama fragmentaria de la vida de Nagaoka Shiki, aquellas miméticas discretas, como las sociales que ya hemos visto, y las directas, en las que aparecen personajes 'tomados' de figuras históricas con sus nombres apenas alterados, como Akutagawa y Tanizaki. ${ }^{17}$

Estos dos personajes son muy importantes para afianzar las relaciones textuales de Shiki en relación con Shiga y para dotar de una verosimilitud compleja al mundo ficcional: en el fragmento de Shiki Nagaoka ... citado antes destaca la mención de su 'nombre real': Naigu Zenchi, que no es otro que el nombre del personaje del cuento de Akutagawa. Los datos biográficos de Naoya Shiga - que el lector no podría descifrar a menos de que cuente con un conocimiento amplio en literatura japonesa — distraen la atención del 'nombre real', el cual no volverá a surgir sino al final del libro para acumularse como otro elemento metaficcional entre la nota periodística de la familia de Shiki y el cuento de Akutagawa.

Pero Bellatin no limita esta relación a un mero guiño nominal, sino que plantea que el propio Akutagawa se inspiró en la vida de Shiki para escribir "La nariz":

16 No desarrollaré este punto en particular, pues requiere de un tratamiento más amplio en lo que se refiere a la estética de Naoya Shiga y esos 'momentos místicos' de Nagaoka Shiki en Ike-no-wo; basta decir que la mención no es gratuita porque se alinea con una visión trascendental de las culturas orientales y es parte de un trabajo que estoy llevando a cabo.

17 Hay una suerte de uso laxo de la romanización del japonés en los nombres de los autores (Junichiro en lugar de Jun'ichirō; Rynosuke en lugar de Ryūnosuke) que va a la par del uso de vocablos japoneses 'deformados', al igual que en El jardín..., con el que constantemente se liga Shiki Nagaoka...; no profundizaré en esta cuestión pero, por supuesto, es otra instancia más para asegurar la verosimilitud de los referentes japoneses en la medida en que el lector posee o no nociones del idioma para cuestionar su sentido, como también afirman Victoria Mariani y Gianna Schmitter al hablar de una 'visión de Oriente' en las novelas de Bellatin (2015: 191). 
Si consideramos La nariz de Rynosuke Akutagawa como un relato inspirado en la vida de nuestro autor, las plegarias de Nagaoka Shiki satisfacían los votos de los fieles que le confiaban, en secreto y por medio de mensajes, sus más caras ilusiones (17).

El juego metaficcional señala lo primordial de la ficción: el cuento de Akutagawa no puede ser biográfico porque no había modo de que Shiki fuera su modelo, pero en el mundo ficcional en el que Shiki existe es posible que un tal 'Rynosuke' se haya inspirado en él.

No obstante, señala Arrieta Domínguez, la fecha con la que se presenta el cuento es 1916, y el momento en el que Shiki comienza su reclusión en el monasterio ocurre cuatro años después (2015: 245); esto, más que un error o incongruencia, señala la posibilidad de leer un desafío a la lógica causal y temporal del texto y, por lo tanto, es un elemento enfocado en cuestionar el grado de realismo asumido por los lectores, lo cual se suma a los intrincados juegos metaficcionales. ${ }^{18}$ Además, no solo se altera el orden causal, sino que la anécdota completa del monasterio constituye una glosa de todo el cuento de Akutagawa y, por extensión, también del "anónimo del siglo XIII" ${ }^{19}$ La traducción de este último proviene de una compilación de Javier Sologuren (2004: 233-235), ${ }^{20}$ de modo que esta es una escritura ya no en segundo grado, sino en tercero, pues

18 Arrieta Domínguez reconoce que los epígrafes y sus respectivos cuentos de origen son los hipotextos del hipertexto que es Shiki Nagaoka... (2015: 244), sin embargo, no explora estas relaciones y se limita a señalar la temporalidad desfasada. Esto es relevante porque, para él, el juego metaficcional se interpreta como un fenómeno propio de la sátira carnavalesca en la que está permitido subvertir la lógica del mundo referencial, y no como un elemento propio de la metaficción que juega con las nociones de realidad para permitirse resignificar los referentes.

19 Schmukler interpreta el rol de los cuentos japoneses como una especie de simultaneidad de los sucesos: "La ficción confunde la procedencia de los textos y alienta una intriga necesaria que no debe claudicar para que el simulacro perdure: ¿cuál es el origen de este autor de ficción? ¿Cuál es su identidad? La respuesta, necesariamente insuficiente, habrá de buscarse en la puesta en crisis de esta noción: aquello que
Akutagawa se basó en el anónimo y este parece prefigurar la vida de Shiki mucho tiempo antes de que 'nazca'. Esto es posible solo mediante la ficción: toda verosimilitud es contingente en tanto no se busque el referente que 'ordena' y, a la vez, simplifica toda significación si la interpretación se reduce a él.

La relación ficcional entre Naoya Shiga y Nagaoka Shiki se extiende entonces, pues el homenaje literario que el Akutagawa ficcional dedica a Nagaoka con el cuento es una versión actualizada de las palabras que Akutagawa dedicó a la obra de Naoya, llevado de la admiración por un personaje histórico hacia el plano en el que Bellatin siempre ha trabajado: el literario, con efectos metaficcionales, en el que la causalidad y la influencia de los intertextos se desdibuja.

Con base en lo anterior, se puede reinterpretar también la presencia de Jun'ichirō Tanizaki, fortuita y de efectos disimulados:

Mientras se encontraba en estas cavilaciones cierta mañana conoció al narrador Tanizaki Junichiro (1886-1965), quien había decidido fijar su residencia en la península de Ikeno. El escritor acudió al kiosko a revelar algunos rollos. Aquel narrador se convirtió en el único artista que Nagaoka Shiki conoció a lo largo de su vida (25).

Es notable el breve momento de introspección de Shiki Nagaoka que Bellatin muestra al lector un par de líneas antes. El estilo narrativo distante y frío que algunos estudiosos observan en el texto queda suspendido en una visión intimista e invasiva de los pensamientos del biografiado. En ellos destaca la aparición de una forma poética

Bellatin reafirma en sus ficciones de autor pseudojaponesas - y fuera de ellas $[\ldots]$ es la proliferación de la desidentidad general" (2013: 7).

20 Daniel Arrieta Domínguez menciona el texto de Sologuren del que Bellatin toma la traducción del anónimo del siglo XIII, sin embargo, no interpreta la lectura del compilador peruano como una clave de la red de elementos con los que se pretende generar verosimilitud respecto de la tradición ‘japonesa' de Nagaoka Shiki (2015: 244, n. 252). 
japonesa por excelencia, el tanka. Este elemento es uno de los pocos identificables de esa 'tradición' a la cual Shiki se apega con fervor. Una vez más, Bellatin elige un referente oscuro: aludir al tanka y no al haikú significa descartar lo reconocible y fácil de ligar con la cultura japonesa desde el conocimiento que de ella existe en América Latina.

La estadía de Shiki en la península de Ikeno se explica a partir de su renuencia a socializar sus textos. En lugar de asumirse como escritor, emprende un negocio de revelado de fotografías y su afición consiste en 'husmear' las fotos de sus clientes. El mismo Tanizaki lo atrapa revisando sus fotos, fascinado porque el afamado escritor capturó exclusivamente baños de todos los estilos:

Al ser sorprendido, Nagaoka Shiki dio como excusa que estaba verificando la calidad del trabajo. Acto seguido señaló que le parecía sumamente curioso el ejercicio que el fotógrafo había llevado a cabo. Tanizaki Junichiro se refirió entonces a aspectos del ensayo que escribia en ese momento. Fue inesperada la celeridad con la que habló de su proyecto. Se dice que era un autor muy proclive a dar explicaciones sobre su obra al primero que se lo preguntase. Que se explayaba de tal manera que en cierta ocasión unos estudiantes que lo abordaron bajo el pretexto de entrevistarlo estuvieron a punto de plagiar el argumento de su novela Diario de un hombre loco (37) [El subrayado es mío].

La crítica ya ha identificado la alusión al famoso ensayo de Tanizaki, In'ei Raisan (El elogio de la sombra, 1933), reconociendo así el diálogo con una de las reflexiones más divulgadas sobre el arte y carácter japonés en voz de uno de sus escritores. ${ }^{21}$ Lo interesante es que Bellatin hace coincidir el momento de la salida de Shiki del monasterio con la publicación de dicho ensayo, al tiempo que introduce información sin contextualizar de la última novela de Tanizaki: en la enunciación no es posible ordenar el momento de publicación del ensayo aludido en relación con Diario de un viejo loco (Futten rojin nikki, 1960), cuyo año de edición no se explicita, es decir, se sugiere un efecto similar al del cuento de Akutagawa. Después, ambos personajes profundizan en la conversación sobre el uso de la fotografía:

Tanizaki Junichiro le contó que había descubierto en la fotografía un aliado que ya no podría abandonar. Habló también de las características que tendrían las cámaras fotográficas de haber sido un invento oriental. Como se puede suponer, este encuentro fue fundamental para la posterior obra de nuestro autor. Algunos lo acusan incluso de copiar a Junichiro Tanizaki, pero investigadores más recientes han demostrado que Nagaoka Shiki no abandonó jamás la tendencia tradicional, y que por lo tanto no es posible advertir, como sucede con la mayor parte de la obra de Tanizaki Junichiro, el menor asomo de influencia extranjera en sus libros (37).

Si hubo un cambio en la obra de Nagaoka Shiki a partir de que los escritores se conocieron, es inevitable la discusión sobre la influencia, la alusión o el plagio, es decir, relaciones intertextuales. Pero no se indaga en estos detalles porque, como textos ficcionales, inaccesibles, las obras de Nagaoka Shiki están ausentes: solo se tienen sus nombres y fechas de publicación, que no concuerdan con las relaciones que Bellatin, como biógrafo, declara y enlaza con referentes reales.

21 Tanizaki reflexiona en este ensayo sobre el carácter 'oriental' apegado al valor de la sombra en la estética japonesa, frente al carácter 'occidental' al que asigna una obsesión por el lustre y lo luminoso. Esta tesis es homogeneizante, puesto que parte del arte y disposición nipones y los extiende al conjunto de 'Oriente', al tiempo que considera 'Occidente' bajo la batuta europea. 
Para Arrieta Domínguez, este encuentro va más allá de la confluencia de dos personajes que simbolizan la dualidad tradición/modernidad. Por una serie de interacciones textuales (2015: 253), el crítico español sostiene la hipótesis de que Nagaoka Shiki es el doble de Jun'ichirō Tanizaki. La superposición es plausible: ambos recurren a la fotografía, un elemento extranjero, para ampliar sus horizontes estéticos —en el texto se insiste en que Shiki se apega a 'la tradición', de la cual se dice poco de forma explícita (la cavilación sobre los tankas)-, y contamos con el entramado de referencias que la crítica ha expuesto y que reubiqué en relación con Naoya Shiga. La presencia de Tanizaki no es gratuita, pues es considerado por muchos estudiosos el mejor escritor japonés del siglo XX; sea como sea, su influencia es innegable y su presencia, recurrente, al hablar de la dicotomía tradición/modernidad. El propio Bellatin reconoce que su inclusión se debe a su valor simbólico, tanto cultural como literario (Hind, 2004: 202).

De tal suerte, los hechos y personas comprobables de la realidad, resignificados, conviven con personajes ficcionales en un tiempo y lugar enmarcados por la ficción, sin embargo, lo que realmente determina la estructura no es otra cosa que la misma textualidad y no los 'datos duros' de la historia: si bien Akutagawa no coincide físicamente con Shiki, es la relación real con Naoya Shiga la que se mimetiza; por otro lado, el encuentro con Tanizaki constituye una especie de reflejo o desdoblamiento, pues ambos simbolizan la continuidad de prácticas escriturales 'tradicionales' frente a incorporaciones estéticas extranjeras y se erigen como modelos de síntesis de los elementos foráneos tanto en lo social como en lo artístico.

No obstante, como se ha argumentado, Bellatin eligió, con inteligencia aguda, distanciar textualmente a Nagaoka de Naoya y apenas conectarlos en el límite discursivo de los hechos biográficos, entre los que destaca el exilio familiar, que en el caso de Naoya se solucionó, pero que para Nagaoka Shiki se volvió un camino de exploración autorreflexivo. Personaje de ficción que escribe sobre lo que se escribe, sus textos nunca se dejan ver más que como influencia 'hacia fuera'. Mucho se ha insistido en la cuestión de la identidad y la 'ficción de autor', lectura válida y bien sustentada, sin embargo, como se ha podido observar, Shiki Nagaoka también podría leerse como una 'Novela del yo': la historia parcial y caprichosa de una identidad artística esquiva, puesta en crisis al situarse en un mundo construido con fragmentos de la modernidad del país oriental.

\section{Conclusiones}

La investigación presentada intenta mostrar cómo, a pesar de la gran cantidad de información que Bellatin sintetiza, nunca tuvo la intención de representar al Japón histórico, sino que aspiraba a crear un mundo turbio en términos referenciales que fuera difícil definir por sí mismo, y conflictivo al tratar de equipararlo con la realidad. Irónicamente, la crítica ha enfatizado todo tipo de distancias entre el Japón de las novelas de Bellatin y la realidad histórica cuando no señala como falsedad las omisiones o la arbitrariedad de los elementos socioculturales mimetizados.

En Shiki Nagaoka... no se representa una cultura en su totalidad y, si se hace, la distancia entre el mundo ficcional y el Japón de la primera mitad del siglo XX resulta insalvable: predomina un vaivén constante en el límite con lo real cuyo objeto es involucrar al lector en esa ambigüedad, en el titubeo entre el saber general y el conocimiento profundo de una cultura. Toda referencia a la exotización se basa en extrapolar la representación y lo escrito hacia lo histórico y en un tratamiento estable de la información cuando no podemos acceder más que a una parcela del mundo al que pertenece Nagaoka Shiki. Al indagar más y más, ha quedado patente que 
no se trata de hablar únicamente de Japón como tema monofónico: Bellatin insta al lector a forzar lo que sabe de esta cultura, a leer entre líneas, no para desvirtuar el texto señalándolo como 'falsedad', sino para ir en pos del otro con la intención de desacostumbrarnos a una relación cómoda con las verdades, las identidades y lo conocido.

Trascender la ficción siempre implica reconstruir discursos y puntos de vista con un enfoque crítico. Al centrarse en un escritor poco conocido de una cultura distante, cuyos referentes están sometidos a todo tipo de adiciones o sustracciones, Bellatin obliga al lector a no conformarse con 'lo que se cuenta' y lo invita a desmontar y reedificar activamente la imagen de Japón, que se transmite de forma soslayada. Esa reflexividad, afortunadamente, se sostiene a expensas de cualquier tendencia posmoderna asignable a la obra e instaura su sentido en una multiplicidad simbólica y escritural que apunta a desafiar las categorías a las que nos aferramos.

\section{REFERENCIAS}

Akutagawa, Ryunosuke (1980), Rashomon y otros cuentos, Buenos Aires, Centro Editor de América Latina.

Arrieta Domínguez, Daniel (2015), Intertextualidad, dialogismo y poética cognitiva en la novela contemporánea: Bernardo Carvalho, Eduardo Lago y Mario Bellatin, [tesis doctoral], Madrid, Universidad complutense de Madrid.

Bellatin, Mario (2001), Shiki Nagaoka: una nariz de ficción, Barcelona, Sudamericana.

Bellatin, Mario (2005), Obras completas, México, Alfaguara.

Berecochea, Ximena (2014), Texto en imagen en la narrativa mexicana contemporánea: el efecto de lo interdisciplinario en seis novelas, [tesis doctoral], Toronto, University of Toronto.

Carlsen, George A. (2015), "Evoking Japan in Mario Bellatin's Cosmopolitan Novels El jardín de la señora Murakami and Shiki Nagaoka: una nariz de ficción", Confluencia, vol. 31, núm. 1, pp. 67-77.

Cherri, Leonel (2019), "Experiencia y fotografía: Shiki Nagaoka de Mario Bellatin", Orbis Tertius, vol. XXIV, núm. 29, pp. 1-13, disponible en: http://sedici.unlp.edu.ar/bitstream/handle/10915/79938/Versión_en_PDF.pdf-PDFA. pdf? sequence $=1$ \&isAllowed $=y$

Doležel, Lubomír (1999), Estudios de poética y la teoría de la ficción, Murcia, Universidad de Murcia.

Durand, Gilbert (2007), La imaginación simbólica, Buenos Aires, Amorrortu.
Fowler, Edward (1988), The Rhetoric of Confession: Shishosetsu in Early Twentieth-Century Japanese Fiction, Berkeley, University of California Press.

Hind, Emily (2004), "Entrevista con Mario Bellatin", Confluencia, vol. 20, núm. 1, pp. 197-204.

López-Calvo, Ignacio (2013), "The Death of the Author through False Translation in Mario Bellatin's Orientalised Japan”, Bulletin of Latin American Research, vol. 32, núm. 3, pp. 339-353.

Mariani, Victoria y Gianna Schmitter (2015), "Mario Bellatin: el Oriente al servicio de un mundo literario extraño, iobjeto del relato o recurso estilístico?", en Nohma Ben Ayad (ed.), La tradición orientalista en América Latina, Chile, Ediciones Altazor.

Pavel, Thomas G. (1995), Mundos de ficción, Venezuela, Monte Ávila.

Rodríguez, Fermín y Mario Bellatin (2006), "Entrevista. Mario Bellatin”, Hispamérica, año 35, núm. 103, pp. 63-69.

Sakai, Kazuya (1968), Japón: hacia una nueva literatura, México, El Colegio de México.

Schmukler, Enrique (2013), "Simluacro, identidad y ficción de autor en dos textos 'japoneses' de Mario Bellatin”, Hispamérica, año 42, núm. 125, pp. 3-10.

Sologuren, Javier (1993), El rumor del origen. Antología general de la literatura japonesa, Lima, Pontificia Universidad Católica del Perú.

Sologuren, Javier (2004), Obras completas, vol. 4, Lima, Pontificia Universidad Católica del Perú.

Waugh, Patricia (1984), Metafiction. The theory and practice of self-conscious fiction, Londres/Nueva York, Routledege.

David Issai Saldaña Moncada. Doctor en Letras por la Universidad Nacional Autónoma de México (UNAM), México. Estudia la parodia, la ironía y la metaficción en la literatura latinoamericana y se interesa en el orientalismo, la narrativa mexicana y la novela japonesa del siglo XX. Actualmente, realiza una estancia posdoctoral con el proyecto "La construcción del vacío: ficciones y símbolos de lo japonés en la narrativa mexicana (1980-2015)", adscrito al Centro Regional de Investigaciones Multidisciplinarias de la UNAM en Cuernavaca, México. Las siguientes son sus publicaciones más recientes: "El vacío de la forma: una interpretación mística de la influencia japonesa en la poesía de Aurelio Asiain" (en Atisbos a lo indecible (Guía para una lectura de la poesía desde la óptica mística), UNAM, 2019); "La profundidad de la percepción: vínculos entre la mística y el budismo zen en Sergio Mondragón" (en Los ríos sonorosos de la palabra (Mística y poesía), UNAM, 2018); y "Dimensiones de la parodia en Dos crímenes de Jorge Ibargüengoitia” (Texto crítico, nueva época, año XX, núm. 40). 


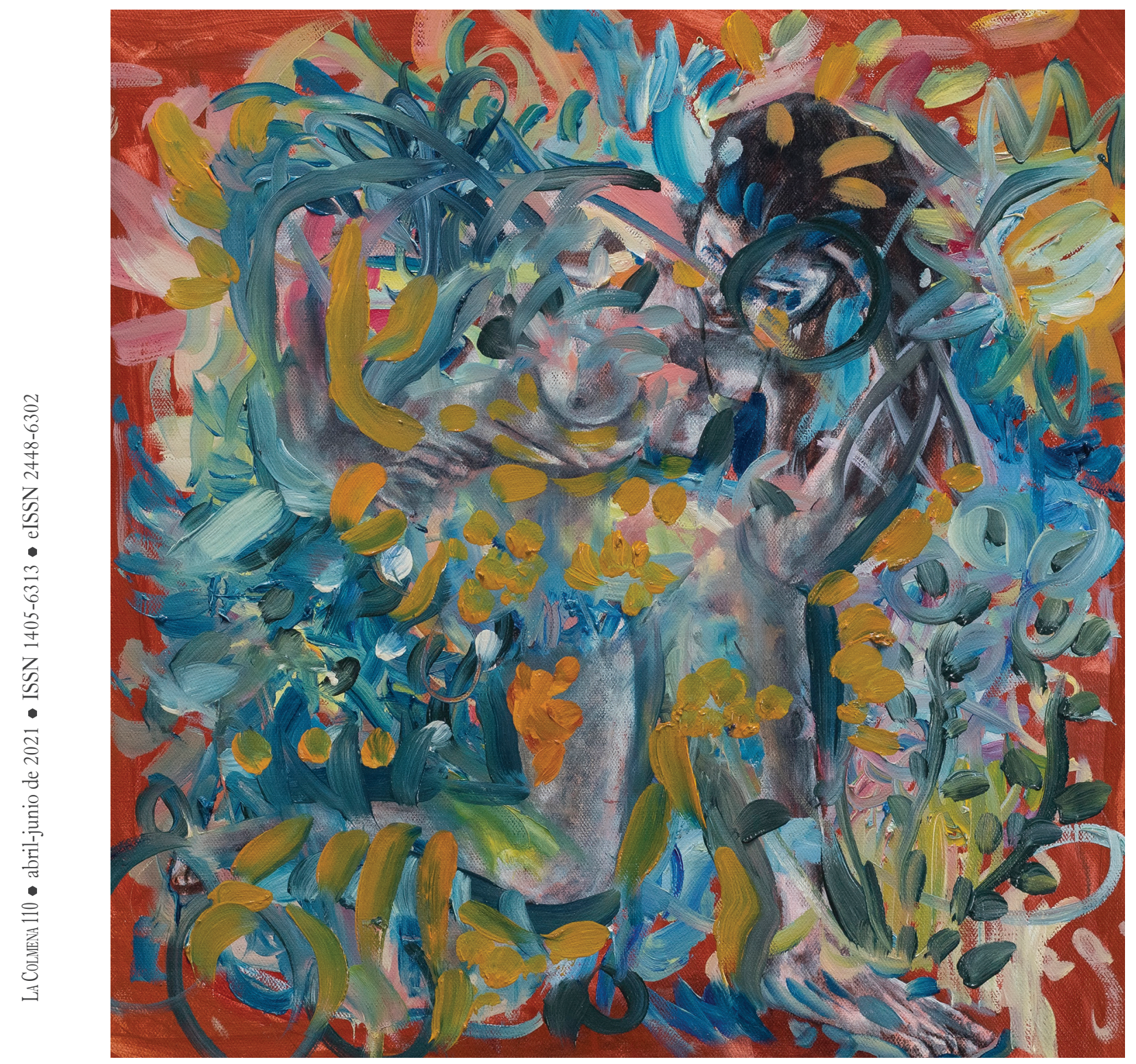

Flores que flotan, de la serie Mar incendiado (2021). Óleo sobre lino: Xilberto Loera-Núñez. Prohibida su reproducción en obras derivadas. 